\title{
Avaliação qualitativa das preparações do cardápio de centros de educação infantil
}

\author{
Qualitative evaluation of the foods served \\ in children education centers
}

Manoela MENEGAZZO'

Korina FRACALOSSI ${ }^{1}$

Ana Carolina FERNANDES²

Neiva Inez MEDEIROS 1

RE S U M O

\section{Objetivo}

Avaliar qualitativamente os aspectos nutricionais e sensoriais das preparações de um cardápio mensal oferecido aos Centros de Educação Infantil de um município da Grande Florianópolis (SC).

\section{Métodos}

Estudo de caso documental, com o cardápio do mês de junho de 2008 como instrumento de pesquisa. O cardápio foi analisado pelo método de Avaliação Qualitativa das Preparações do Cardápio, adaptado à realidade dos Centros de Educação Infantil, com base nas diretrizes do Guia Alimentar para a População Brasileira.

\section{Resultados}

Observou-se que a alimentação oferecida aos pré-escolares, no almoço e no jantar, apresenta baixa oferta de carnes gordurosas e frituras, não tem excesso de alimentos sulfurados e nem monotonia de cores. Porém, há alta oferta de carboidratos simples e ácidos graxos trans, pouca oferta de frutas, legumes e verduras e monotonia de cores nos lanches.

\section{Conclusão}

A elaboração do cardápio necessita de um acompanhamento mais rigoroso para que as preparações estejam adequadas a todas recomendações do Guia Alimentar para a População Brasileira.

Termos de indexação: Alimentação escolar. Pré-escolar. Saúde da criança. Qualidade dos alimentos.

\footnotetext{
1 Associação Educacional Luterana Bom Jesus, Programa Pós-Graduação em Gestão em Unidades de Alimentação e Nutrição, Departamento de Nutrição. Unidade Saguaçu II, R. Mafra, 84, Saguaçu 89221-665, Joinville, SC, Brasil. Correspondência para/Correspondence to: M. MENEGAZZO. E-mail: <manoelamenegazzo@yahoo.com.br>.

2 Universidade Federal de Santa Catarina, Núcleo de Pesquisa de Nutrição em Produção de Refeições. Florianópolis, SC, Brasil.
} 
244 M. MENEGAZZO et al.

\section{A B S T R A C T}

\section{Objective}

This study assessed the nutritional and sensory aspects of the preparations served during a month at the Children Education Centers of one city from Grande Florianópolis, Santa Catarina, Brazil.

\section{Methods}

This case study used the method Qualitative Evaluation of Menu Components, adapted to the reality of Children Education Centers and based on the recommendations of the Brazilian Food Guide, to assess the menu from June 2008.

\section{Results}

The foods served to the preschool children at lunch and supper are low in high-fat meats and fried preparations and do not contain too many sulfur-rich foods or color monotony. However, the simple carbohydrate and trans fatty acid contents are high, the amounts of fruits and non-starchy vegetables are low and the snacks are not colorful.

\section{Conclusion}

The menu needs to be monitored thoroughly to ensure that the preparations meet all the recommendations of the Brazilian Food Guide.

Indexig terms: School feeding. Child, preschool. Child health. Food quality.

\section{N T R O D U Ç Ã O}

Na infância, a alimentação qualitativa e quantitativamente adequada é essencial para garantir o crescimento e o desenvolvimento da criança, pois proporciona energia e nutrientes necessários para o bom desempenho de suas funções e para a manutenção da saúde ${ }^{1,2}$.

No Brasil, há poucos anos, os principais desafios, em saúde pública, relacionados à alimentação infantil eram a desnutrição e as deficiências de micronutrientes ${ }^{3,4}$. No entanto, recentemente, a evolução das Doenças Crônicas Não-Transmissíveis (DCNT) e o aumento da prevalência de obesidade vêm sendo um desafio adicional à segurança alimentar e nutricional, visto que essas doenças já podem ser observadas com frequência nas faixas etárias mais jovens, incluindo os pré-escolares ${ }^{3}$. O hábito de assistir à televisão várias horas ao dia, a difusão dos jogos eletrônicos, o abandono do aleitamento materno antes dos seis meses de idade e a utilização de alimentos formulados na alimentação infantil são fatores que devem ser considerados para o desenvolvimento desse quadro, bem como a substituição, no nível doméstico, dos alimentos processados pelos alimentos industrializados, que geralmente têm maior densidade energética, açúcares e gorduras ${ }^{5}$.
Segundo a Organização Mundial de Saúde (OMS), as prevalências de sobrepeso e de obesidade estão aumentando em diversas partes do mundo em ritmo alarmante ${ }^{6}$. Entretanto, o combate às DCNT e à obesidade deve ser conjugado com esforços para a reversão da prevalência da desnutrição infantil e para o controle das deficiências de micronutrientes, pois essas doenças ainda acometem considerável parcela da população ${ }^{7}$. Com o intuito de minimizar essa situação, deve-se promover ações de educação alimentar e nutricional para incentivar os hábitos alimentares saudáveis.

Na faixa etária dos pré-escolares são incorporados novos hábitos alimentares, o que está diretamente relacionado ao descobrimento de sabores, texturas e cores - experiências sensoriais que irão influenciar o padrão alimentar a ser adotado pela criança². Sendo assim, o ambiente escolar é fundamental para a determinação desses hábitos, visto que a criança permanece no local durante um ou dois períodos do dia, convivendo com educadores, cuidadores e com outras crianças que irão auxiliar e influenciar a formação de seus valores e de seu estilo de vida, entre eles a alimentação ${ }^{8}$. Ao mesmo tempo, esse ambiente deve estabelecer práticas de saúde que incluam 
hábitos alimentares saudáveis, através do fornecimento de refeições nutricionalmente adequadas e seguras sob o ponto de vista higiênico-sanitário, além da inserção de conceitos de alimentação saudável na prática educativa9.

Para tanto, o Programa Nacional de Alimentação Escolar (PNAE) tem como objetivo contribuir para o crescimento e o desenvolvimento biopsicossocial, para a aprendizagem, para o rendimento escolar e para a formação de práticas alimentares saudáveis, por meio de ações de educação alimentar e nutricional, além da oferta de refeições que atendam às necessidades nutricionais dos escolares durante o período letivo ${ }^{10}$. Para que o cardápio oferecido nos Centros de Educação Infantil (CEI) atenda esses objetivos, é necessário realizar um planejamento que considere não só os aspectos nutricionais, mas também os aspectos sensoriais, como as cores, a textura, os sabores, a combinação de preparações, o tipo de alimento e as técnicas de preparo"1.

Segundo o PNAE, os alunos que permanecem em período integral nos $C E I$ devem receber, no mínimo, alimentação referente a 70,0\% das necessidades nutricionais diárias ${ }^{10}$. Porém, os CEI atendem crianças de dois a seis anos, cujas recomendações nutricionais diferem segundo a faixa etária ${ }^{12}$, o que dificultaria uma avaliação somente expressa pela quantidade de nutrientes consumidos. Além disso, profissionais da saúde pública e formuladores de políticas em alimentação e nutrição estimulam o desenvolvimento de recomendações para uma alimentação saudável baseada em alimentos, não em nutrientes ${ }^{3}$. Conforme as "Leis da Alimentação", descritas por Pedro Escudero, deve-se observar, além da quantidade e da adequação nutricional dos alimentos, a qualidade e a harmonia entre eles ${ }^{13}$.

O Guia Alimentar para a População Brasileira traz diretrizes que fornecem informações para a promoção do consumo de alimentos saudáveis, com o objetivo de reduzir a ocorrência de doenças na população brasileira maior de dois anos $^{3}$. Assim, a fim de se analisarem os itens pertinentes à qualidade de cardápios elaborados e os aspectos nutricionais e sensoriais, foi desenvolvido, por Veiros \& Proença ${ }^{11}$ o método de Avaliação Qualitativa das Preparações do Cardápio (AQPC).

O método AQPC visa a auxiliar o profissional na construção de um cardápio mais adequado do ponto de vista nutricional e de alguns aspectos sensoriais dentro dos parâmetros de saúde cientificamente preconizados ${ }^{11}$.

Diante do exposto, o presente estudo teve como objetivo avaliar qualitativamente os aspectos nutricionais e sensoriais das preparações de um cardápio mensal oferecido às crianças nos Centros de Educação Infantil do Município da Palhoça (SC).

\section{M É T O D O S}

Foi realizado um estudo de caso documental, cujo o instrumento de pesquisa foi o cardápio do mês de junho de 2008 oferecido para as crianças de dois a seis anos que frequentam em período integral os CEI de um município da Grande Florianópolis (SC).

A escolha do cardápio foi realizada entre aqueles referentes ao período de outubro de 2007 a setembro de 2008, com o intuito de selecionar o cardápio que oferecesse preparações comumente servidas durante o ano letivo. Assim, foram definidos os seguintes critérios de avaliação: (a) estrutura do cardápio, contendo, no mínimo, quatro semanas; (b) meses sem feriados/pontos facultativos ou retorno às atividades escolares, visto que a entrega dos gêneros sofre adaptações e, com isso, a qualidade nutricional e sensorial do cardápio é comprometida; (c) cardápios sem preparações diferenciadas oferecidas em datas festivas; (d) cardápios com o menor número de preparações típicas de estações do ano, como as sopas no inverno. Assim, observou-se que o cardápio que mais atendeu os critérios foi o de junho de 2008.

A avaliação do cardápio utilizou o método de Avaliação Qualitativa das Preparações do Car- 
dápio ${ }^{11}$, adaptado à realidade de CEI com base nas diretrizes do Guia Alimentar para a População Brasileira.

Para subsidiar a avaliação, foram consultadas as fichas técnicas do receituário padrão existente nos $\mathrm{CEl}$, os rótulos dos gêneros alimentícios utilizados nas preparações do cardápio e as tabelas de composição nutricional. Assim, foi possível coletar os dados sobre o modo de preparo das refeições, os ingredientes e a composição nutricional dos alimentos e produtos.

Considerou-se que a criança realiza quatro refeições no CEl e uma refeição fora do ambiente escolar, uma vez que o Guia Alimentar para a População Brasileira recomenda a realização de cinco refeições diárias ${ }^{3}$.

Desse modo, os critérios para cada item da avaliação qualitativa do cardápio foram:

1. Presença de frutas ou preparações à base de frutas: o Guia Alimentar para a População Brasileira recomenda a ingestão de três porções de frutas por dia ${ }^{3}$. Considerando-se que no CEI são oferecidas quatro refeições e que a criança deve ainda realizar pelo menos uma refeição em casa, esse critério foi classificado como adequado quando no CEl foram ofertadas duas porções de frutas por dia.

2. Presença de verduras e legumes ou como ingredientes principais da preparação (sopas, canjas, tortas, entre outros que não tiveram os legumes e verduras como principais ingredientes foram desconsiderados): esse critério segue o mesmo princípio do anterior e foi classificado como adequado quando no CEl foram servidas duas porções de verduras e legumes por dia. No caso de saladas mistas (ex: alface com tomate), foi considerada apenas uma oferta.

3. Presença de folhosos: só foram analisados os folhosos servidos crus. Esse critério foi classificado como adequado quando no CEI foi oferecida pelo menos uma porção de folhosos por dia.

4. Monotonia de cores: o cardápio avaliado apresenta grandes refeições e lanches, cujas pre- parações contêm ingredientes distintos conforme o tipo de refeição e, com isso, cores diferentes. Dessa forma, avaliou-se esse critério em dois momentos: monotonia de cores dos lanches e monotonia de cores das grandes refeições (almoço e jantar). Nessa avaliação, as carnes e o feijão não foram considerados, com exceção dos dias em que houve oferta de um prato único, como o carreteiro. Esse critério foi considerado quando pelo menos $50 \%$ das preparações apresentaram cores semelhantes.

5. Presença de alimentos ricos em enxofre: foram analisados os acompanhamentos (com exceção do feijão, visto que o guia alimentar recomenda o consumo diário ${ }^{3}$ ) e as saladas com base na seguinte lista de alimentos sulfurados: abacate, acelga, aipo, alho, amendoim, batata-doce, brócolis, castanha, cebola, couve-de-bruxelas, couve-flor, ervilha, feijão, gengibre, goiaba, jaca, lentilha, maçã, melancia, melão, milho, mostarda, nabo, nozes, ovo, rabanete, repolho e uva ${ }^{14}$. Esse critério foi classificado como destaque quando mais de um alimento ou preparação rico em enxofre foi oferecido no mesmo dia.

6. Presença de doces: segundo a diretriz do Guia Alimentar para a População Brasileira, o consumo máximo diário de alimentos do grupo dos açúcares e doces é de uma porção ${ }^{3}$. Portanto, receberam destaque os dias em que a oferta foi superior a uma porção. Além das sobremesas, foram consideradas algumas preparações pré-prontas que contêm açúcar como um dos seus principais ingredientes, como bebidas lácteas e achocolatados, suco artificial, gelatina, pudim, mingau e doce de leite.

7. Presença de carnes gordurosas ou frituras: esse critério foi classificado como destaque quando pelo menos $25,0 \%$ do total de opções de carnes e do total de opções de acompanhamentos quentes eram carnes gordurosas ou frituras em cada refeição (almoço e jantar). Consideram-se carnes gordurosas aquelas em que a gordura excede 50,0\% do total energético, como picanha, fraldinha, acém, capa de filé, costela, contrafilé, paleta, pescoço, ponta de agulha e vísceras ${ }^{15}$. 
8. Presença de alimentos e preparações que contenham ácidos graxos trans: visto não haver níveis seguros de consumo desse tipo de ácido graxo, a avaliação foi qualitativa, independentemente da quantidade encontrada. Todos aqueles alimentos que apresentavam ácidos graxos trans em algum ingrediente da preparação foram considerados.

Para aplicação do método AQPC, as preparações do cardápio foram, primeiramente, classificadas conforme cada critério, utilizando-se a tabela de composição nutricional, a leitura de rótulos dos ingredientes e as fichas técnicas do receituário padrão, bem como a observação direta do modo de preparo.

A avaliação do cardápio foi realizada a partir da observação do percentual de ocorrência diária dos alimentos ou preparações relativos a cada critério, e, assim, analisou-se se cada critério foi atendido naquele dia. Em seguida, foi contabilizado, por semana, o número de dias em que houve a ocorrência de cada critério analisado e, por fim, calculou-se a porcentagem de ocorrência, considerando todos os dias do mês.

\section{RESULTADOSE DISCUSSÃO}

Observou-se baixa oferta de frutas, legumes e verduras, pois em apenas um dia do mês foi oferecida mais de uma porção de fruta (4,0\%), em quatro dias foi servida salada de folhosos $(16,0 \%)$ e em apenas doze dias $(48,0 \%)$ foram oferecidas duas porções de verduras e legumes (Tabela 1). Resultados semelhantes foram encontrados em um estudo realizado por Barbosa et al. ${ }^{16}$, no qual as crianças ingeriam 2,2 porções de verduras e 1,2 porção de frutas por dia ${ }^{16}$. Em outro estudo, Munoz et al. ${ }^{17}$ também perceberam que, entre as crianças e os adolescentes avaliados, somente $36,0 \%$ apresentaram um consumo adequado de verduras e $30,0 \%$ de frutas.

Na Pesquisa de Orçamento Familiar 20022003, realizada pelo Instituto Brasileiro de Geografia e Estatística, observou-se que as famílias brasileiras não têm o hábito de ingerir frutas, legumes e verduras: apenas $2,3 \%$ das calorias ingeridas correspondiam a esses alimentos, o que não representa nem um terço da recomendação diária ${ }^{18}$.

O baixo consumo de frutas, verduras e legumes por crianças brasileiras, conforme observado neste e nos demais estudos citados, mostra-se preocupante e exige ações para o aumento desse consumo, uma vez que esses alimentos essenciais para o desenvolvimento infantil por serem fontes de vitaminas, minerais e fibras alimentares. Além disso, a ingestão de frutas, legumes e verduras é um fator protetor contra o desenvolvimento da obesidade, devido à menor densidade energética desses alimentos e à sua capacidade de gerar sensação de saciedade, em decorrência da atuação das fibras alimentares. As fibras também têm ação hipocolesterolêmica e, quando associadas ao consumo de água, previnem a constipação ${ }^{3}$.

Tabela 1. Resultado da análise do cardápio do mês de junho de 2008 oferecido aos Centros de Educação Infantil de um município da Grande Florianópolis (SC), 2008, quanto ao número de dias em que houve a ocorrência de cada critério considerado.

\begin{tabular}{|c|c|c|c|c|c|c|c|c|c|c|}
\hline \multirow[b]{2}{*}{ Semanas } & \multirow[b]{2}{*}{ Dias (n) } & \multirow[b]{2}{*}{ Fruta } & \multirow{2}{*}{$\begin{array}{c}\text { Legumes + } \\
\text { verduras }\end{array}$} & \multirow[b]{2}{*}{ Folhosos } & \multicolumn{2}{|l|}{ Cores } & \multirow{2}{*}{$\begin{array}{l}\text { Ricos em } \\
\text { enxofre }\end{array}$} & \multirow[b]{2}{*}{ Doce } & \multirow{2}{*}{$\begin{array}{c}\text { Carne } \\
\text { gordurosa + } \\
\text { fritura }\end{array}$} & \multirow{2}{*}{$\begin{array}{c}\text { Ácidos } \\
\text { graxos } \\
\text { trans }\end{array}$} \\
\hline & & & & & $\begin{array}{c}\text { Iguais } \\
\text { almoço/jantar }\end{array}$ & $\begin{array}{l}\text { Iguais } \\
\text { lanches }\end{array}$ & & & & \\
\hline Semana 1 & 5 & 1 & 4 & 1 & 1 & 3 & - & 5 & 1 & 5 \\
\hline Semana 2 & 5 & - & 2 & 1 & - & 3 & 1 & 5 & - & 5 \\
\hline Semana 3 & 5 & - & 1 & 1 & 1 & 3 & - & 5 & 1 & 5 \\
\hline Semana 4 & 5 & - & 2 & 1 & - & 3 & - & 4 & - & 5 \\
\hline Semana 5 & 5 & - & 3 & - & 1 & 5 & - & 4 & - & 5 \\
\hline Total dias & 25 & 1 & 12 & 4 & 3 & 17 & 1 & 23 & 2 & 25 \\
\hline \% de ocorrência & & 4 & 48 & 16 & 12 & 68 & 4 & 92 & 8 & 100 \\
\hline
\end{tabular}


A oferta de doces foi considerada além das recomendações citadas nos critérios, visto que esteve presente em $92 \%$ dos dias avaliados: dos 25 dias do cardápio, em 23 foram oferecidas pelo menos duas preparações industrializadas que continham açúcar como um dos seus principais ingredientes. Em um estudo realizado por Barbosa et al. ${ }^{16}$, o consumo de açúcar foi três vezes maior que o recomendado pela pirâmide alimentar infantil proposta por Philippi et al. ${ }^{2}$. Em outro estudo, Aquino \& Philippi ${ }^{19}$ avaliaram o consumo alimentar das crianças em diferentes faixas de renda e foi constatado que o consumo de açúcar é alto em todas elas, porém é maior nas famílias de menor poder aquisitivo.

O alto consumo de açúcar por crianças, além de ser prejudicial para o estado nutricional, é fator de risco para desenvolvimento de doenças crônicas não transmissíveis, tal como diabetes, e predispõe ao aparecimento de cáries. Em estudo realizado em Florianópolis (SC) sobre aspectos comportamentais e severidade de cárie, foi observado que as crianças que consumiam produtos açucarados duas a três vezes por dia apresentavam 4,41 vezes mais chance de ter alta severidade de cárie quando comparadas às crianças que consumiam esses produtos no máximo uma vez ao $\operatorname{dia}^{20}$.

Em relação aos alimentos e preparações que contêm Ácidos Graxos Trans (AGT), observou-se semelhança com a oferta de doces, isto é, houve a oferta desses alimentos pelo menos uma vez em todos os dias avaliados (100\%).

Os AGT sempre estiveram presentes na alimentação humana, por meio do consumo de alimentos provenientes de animais ruminantes, cujas bactérias do rúmen produzem naturalmente esses ácidos graxos. Os AGT naturais parecem não causar problemas na saúde humana, mas a maior parte de AGT consumidos pelos humanos provém das gorduras produzidas pela hidrogenação de óleos - processo largamente utilizado nas indústrias de alimentos ${ }^{21}$. Esse tipo de AGT, que causa efeitos adversos à saúde, é encontrado em gorduras vegetais hidrogenadas, margarinas, cremes vegetais, pães, biscoitos, batatas fritas, massas, sorvetes, pastéis e bolos, ou seja, em alimentos amplamente consumidos pelas crianças nos $\mathrm{CE}^{22}$.

O consumo dos ácidos graxos trans industriais tem sido associado ao aparecimento de Doenças Cardiovasculares (DVC) e a prejuízos no processo de crescimento e desenvolvimento das crianças. O principal efeito metabólico desses ácidos graxos é a ação hipercolesterolêmica, que é a elevação do colesterol total e da proteína de baixa densidade (Low Density Lipoprotein - LDL), reduzindo a lipoproteína de alta densidade (Hight Density Lipoprotein - HDL) e resultando em um aumento da relação LDL/HDL. Acredita-se, também, que os ácidos graxos trans podem afetar o processo de desenvolvimento da criança pela deficiência do ácido araquidônico e docohexaenoico que estão envolvidos na função psicomotora ${ }^{23}$. Desse modo, a Estratégia Global para a Alimentação Saudável, Atividade Física e Saúde, lançada em 2004 pela Organização Mundial de Saúde (OMS), recomenda limitar a ingestão de gordura, substituir as gorduras saturadas por insaturadas e eliminar os ácidos graxos trans ${ }^{24}$.

A oferta excessiva de doces e alimentos e preparações que contenham AGT pode ser atribuída, em parte, à utilização de alimentos industrializados devido à facilidade em armazená-los, prepará-los e servi-los. O aumento do consumo de alimentos industrializados, ricos em açúcares simples e gorduras, com elevado valor energético, pode ser fator de risco para doenças crônicas, inclusive a obesidade ${ }^{25}$.

Em relação à presença de carnes gordurosas ou frituras, houve oferta somente em dois dias do cardápio, em que se serviu almôndega frita. A baixa oferta desses alimentos é avaliada como positiva para a promoção da saúde do pré-escolar, visto que o consumo excessivo é um fator de risco para doenças cardiovasculares ${ }^{26}$.

No cardápio avaliado, são oferecidos somente cortes de carne magra, como lagarto em bife e patinho moído e em cubos, bem como peito de frango sem pele e sem osso, sobrecoxa sem 
pele e sem osso e filé de peixe, também consideradas carnes não gordurosas.

Além do tipo de carne utilizada, esse critério considera o modo de cocção. Observou-se que na elaboração do cardápio prioriza-se o preparo de carnes cozidas, assadas ou ensopadas. Ressalta-se que o modo de preparo é padronizado pelas fichas técnicas do receituário padrão, no qual consta que as carnes ensopadas não devem ser previamente fritas, o óleo deve ser utilizado em pequena quantidade e a gordura aparente deve ser retirada.

O Guia Alimentar para a População Brasileira sugere uma redução na energia proveniente das gorduras, com maior preocupação na diminuição do consumo do grupo das carnes vermeIhas, ovos e produtos lácteos, como leite e queijos, pois são alimentos ricos em gordura saturada ${ }^{3}$.

Além dos aspectos estritamente nutricionais, verificou-se também a qualidade sensorial associada à nutricional por meio da observação do aspecto visual das preparações e dos alimentos ricos em enxofre. Nas refeições de almoço e jantar, foi observada semelhança de cores das preparações em apenas três dias do mês (12,0\%). Porém, em relação aos lanches, a ocorrência foi de $68,0 \%$, o que caracterizou a monotonia de cores na maioria dos dias. Acredita-se que esse resultado seja consequência da oferta de alimentos industrializados, prontos para o consumo, que apresentam pouca diversidade de cores e sabores.

A monotonia de cores pode interferir na aceitação das preparações, visto que o primeiro contato que a criança tem com o alimento é o visual e que a uniformidade de cores diminui a atratividade do alimento. Além disso, a variedade de cores vai ao encontro das recomendações nutricionais de compor o prato de maneira mais colorida possível, com o intuito de garantir a ingestão de uma maior diversidade de vitaminas e minerais ${ }^{3,27}$.

São desenvolvidas ações em mais de trinta países com o objetivo de sensibilizar a população para a importância de consumir diariamente pelo menos cinco porções de frutas, legumes e verduras, de cores variadas, a fim de contribuir para a prevenção de doenças crônicas associadas à alimentação. Nesse contexto, está o programa " 5 ao dia" - surgido nos Estados Unidos em 1991 -, que recomenda o consumo de refeições coloridas e com variedade de alimentos, de maneira que seja evitada a monotonia alimentar ${ }^{28}$.

Quanto à oferta de alimentos ricos em enxofre, desconsiderando-se o feijão, observou-se que somente em um dia do mês $(4,0 \%)$ foram ofertados alimentos sulfurados em excesso. Esse resultado é considerado positivo, uma vez que a oferta excessiva de alimentos sulfurados pode provocar desconforto gástrico nos pré-escolares ${ }^{14}$.

Os itens observados neste estudo que não atingiram os critérios de qualidade nutricional, tais como a baixa oferta de frutas, verduras e legumes e o alto consumo de doces e ácidos graxos trans, coincidem com os hábitos alimentares de indivíduos obesos, que geralmente têm alto consumo de alimentos ricos em gordura, colesterol e carboidratos simples, são pobres em fibras e têm elevada densidade energética29,30. A obesidade pode levar ao desenvolvimento de patologias como diabetes tipo 2, hipertensão, dislipidemia e síndrome metabólica, além de influenciar a autoestima e afetar a performance escolar e os relacionamentos ${ }^{31}$.

A monotonia de cores observada nos lanches pode comprometer, também, a variedade de nutrientes ingeridos pelas crianças, bem como desestimular o consumo da alimentação escolar. Essa monotonia - provavelmente causada pelo oferecimento de produtos industrializados e com baixa diversidade de sabores - está ainda relacionada à alta oferta de açúcares e ácidos graxos trans e pode indicar a necessidade de serem revistos os padrões de aquisição dos alimentos oferecidos na alimentação escolar.

Assim, observa-se a necessidade de um melhor planejamento de cardápio nos CEI, com o intuito de prevenir o aparecimento de doenças crônicas não-transmissíveis nas crianças, que realizam a maior parte de suas refeições no local. 


\section{O N CLUSÃ O}

A alimentação na infância assume caráter decisivo na formação de hábitos alimentares saudáveis, bem como no possível desenvolvimento de doenças que, futuramente, podem comprometer a saúde.

Neste estudo, observou-se que a alimentação oferecida às crianças nos Centros de Educação Infantil do Município avaliado apresenta baixa oferta de carnes gordurosas e frituras, não tem excesso de alimentos sulfurados e nem monotonia de cores no almoço e no jantar. Porém, há alta oferta de carboidratos simples e ácidos graxos trans, pouca oferta de frutas, legumes e verduras e monotonia de cores nos lanches, o que destaca a necessidade de um acompanhamento mais rigoroso na elaboração dos cardápios propostos.

Deve-se ressaltar, no entanto, que, como o horário de permanência da criança no CEI não é suficiente para o atendimento total das recomendações nutricionais, a família assume parte dessa responsabilidade ao oferecer, em casa, ao menos uma refeição. Para isso, são necessárias atividades e palestras de orientação nutricional para os pais ou responsáveis dessas crianças.

Torna-se fundamental, portanto, estimular o consumo de diferentes tipos de alimentos e tentar aumentar o interesse da criança por novos alimentos e/ou preparações. Assim, além de reformulações no cardápio, sugere-se que sejam desenvolvidas aulas práticas envolvendo a criança com o alimento.

Estudos que avaliem o consumo e a frequência alimentar das crianças são necessários, pois, assim, determinadas providências poderão ser tomadas a fim de melhorar a alimentação dos pré-escolares.

\section{OLABORADORES}

M. MENEGAZZO e K. FRACALOSSI realizaram o levantamento e revisão da literatura, a análise dos dados, e a redação do artigo. A.C. FERNANDES auxiliou na adaptação do método, na análise e discussão dos dados, e na redação do artigo. N.I. MEDEIROS orientou o desenho metodológico da investigação e revisou o artigo.

\section{REFERÊ NCIAS}

1. Spinelli MGN, Goulart RMM, Santos ALP, Gumiero LDC, Farhud CC, Freitas EB, et al. Consumo alimentar de crianças de 6 a 18 meses em creches. Rev Nutr [Internet]. 2003 [acesso 2009 jan 9]; 16(4):409-14. Disponível em: <http://www.scielo. br>. doi: 10.1590/S1415-52732003000400004.

2. Philippi ST, Cruz ATR, Colucci ACA. Pirâmide alimentar para crianças de 2 a 3 anos. Rev Nutr [Internet]. 2003 [acesso 2009 jan 9]; 16(1):5-19. Disponível em: <http://www.scielo.br>. doi: 10.15 90/S1415-52732003000100002.

3. Brasil. Ministério da Saúde. Secretaria de Atenção à Saúde. Guia Alimentar para a população brasileira: promovendo a alimentação saudável. Brasília: MS; 2006 [acesso 2008 jun 20]. Disponível em: <http://dtr2004.saude.gov.br/nutricao/guia_ conheca.php>

4. Oliveira MCF, Silva PL, Mesquita MA. Analisando o padrão alimentar e o estado nutricional de pré-escolares matriculados na creche do município de Descoberto, MG. Rev Nutr Brasil. 2006; 5(3):150-9.

5. Escrivão MAMS, Oliveira FLC, Taddei JAAC, Lopez FA. Obesidade exógena na infância e na adolescência. J Pediatr. 2000; 76 (Supl.3):305-10.

6. World Health Organization. Physical status: the use and interpretation of Anthropometry. Report of a WHO Expert Committee. Geneva: WHO; 1995. WHO Technical Report Series.

7. Oliveira C, Fisberg M. Obesidade na infância e adolescência: uma verdadeira epidemia. Arq Bras de Endocrinol Metab [Internet]. 2003 [acesso 2009 jan 9]; 47(2):107-8. Disponível em: <http://www. scielo.br>. doi: 10.1590/S0004-2730200300020 0001.

8. Sociedade Brasileira de Pediatria. Manual de orientação: obesidade na infância e adolescência. São Paulo: SBP; 2008 [acesso 2008 jul 24]. Disponível em: <http://www.sbp.com.br/PDFs/Man\%20 Nutrologia_Obsidade.pdf>.

9. Alves FS, Albiero KA. Formação e desenvolvimento de hábitos alimentares em crianças pela educação nutricional. Nutr Pauta [Internet]. 2007 [acesso 2008 nov 15]; 15(82). Disponível em: <http://www. nutricaoempauta.com.br/lista_artigo.php?cod= 554>. 
10. Brasil. Ministério da Educação. Fundo Nacional de Desenvolvimento da Educação. Resolução n 38 de 16 de julho de 2009. [acesso 2009 ago 10]. Disponível em: <http://www.territoriosdacidadania. gov.br/portal/saf/arquivos/view/alimenta-o-escolar/ RES38_FNDE.pdf>.

11. Proença RPC, Sousa AA, Veiros MB, Hering B. Qualidade nutricional e sensorial na produção de refeições. Florianópolis: Editora da UFSC; 2005.

12. Institute of Medicine of the National Academies. Dietary reference intakes for energy, carbohydrate, fiber, fat, fatty acids, cholesterol, protein, and amino acids. [cited 2009 Jan 9]. Available from: <http://www.iom.edu/Object.File/ Master/54/397/ DRIs. Macronutrients.pdf>.

13. Irala CH, Fernandez PM, Recine E. Manual para escolas: a escola promovendo hábitos alimentares saudáveis. Brasília: Universidade de Brasília; 2001.

14. Reis NT. Nutrição clínica: sistema digestório. Rio de Janeiro: Livraria Rubio; 2003.

15. Philippi ST. Nutrição e técnica dietética. Barueri: Manole; 2003.

16. Barbosa RMS, Croccia C, Carvalho CGN, Franco VC, Salles-Costa R, Soares EA. Consumo alimentar de crianças com base na pirâmide alimentar brasileira infantil. Rev Nutr [Internet]. 2005 [acesso 2009 jan 9]; 18(5):633-41. Disponível em: <http:// www.scielo.br>. doi: 10.1590/\$1415-52732005 000500006.

17. Munoz KA, Krebs-Smith SM, Ballard-Barbash R, Cleveland LE. Food intakes of US children and adolescents compared with recommendations. Pediatrics. 1997; 100(3 Pt1):323-9.

18. Levy-Costa RB, Sichieri R, Pontes NS, Monteiro CA. Disponibilidade domiciliar de alimentos no Brasil: distribuição e evolução (1974-2003). Rev Saúde Pública [Internet]. 2005 [acesso 2009 jan 9]; 39(4):530-40. Disponível em: <http://www. scielo.br>. doi: 10.1590/S0034-891020050004 00 003.

19. Aquino RC, Philippi ST. Consumo infantil de alimentos industrializados e renda familiar na cidade de São Paulo. Rev Saúde Pública [Internet]. 2002 [acesso 2009 jan 9]; 36(6):655-60. Disponível em: <http://www.scielo.br>. doi: 10.1590/S0034-89 102002000700001.

20. Peres KGA, Bastos JRM, Latorre MRDO. Severidade de cárie em crianças e relação com aspectos sociais e comportamentais. Rev Saúde Pública [Internet]. 2000 [acesso 2009 jan 9]; 34(4):402-8. Disponível em: <http://www.scielo.br>. doi: 10.1590/50034-89 102000000400014.

21. Koletzko B, Decsi T. Metabolic aspects of trans fatty acids. Clini Nutr [Internet]. 1997 [cited 2009 Jan 10]; 16 (5):229-37. Available from: <http://www. sciencedirect.com>. doi: 10.1016/S0261-5614(97) 80034-9.

22. Mondini L, Monteiro CA. Mudanças no padrão de alimentação. In: Monteiro CA. Velhos e novos males da saúde no Brasil: a evolução do país e suas doenças. São Paulo: Hucitec; 2000.

23. Chiara VL, Silva R, Jorge R, Brasil AP. Ácidos graxos trans: doenças cardiovasculares e saúde materno-infantil. Rev Nutr [Internet]. 2002 [acesso 2009 jan 9]; 15(3):341-9. Disponível em: <http://www. scielo.br>. doi: 10.1590/S1415-527320020003 00010.

24. World Health Organization. Global strategy on diet, physical activity and health. Geneva; 2004 [cited 2009 Jan 10]. Available from: <www.who.int/ dietphysicalactivity/strategy/eb11344/strategy_ english_web.pdf>.

25. Casanova M. Prevalência de sobrepeso incluindo obesidade em escolares entre 6 a 10 anos de idade matriculados no ensino público municipal de Balneário Camboriú, Santa Catarina, Brasil [dissertação]. Florianópolis: Universidade Federal de Santa Catarina; 2007.

26. Lima FEL, Menezes TN, Tavares MP, Szarfarc SC, Fisberg RM. Ácidos graxos e doenças cardiovasculares: uma revisão. Rev Nutr [Internet]. 2000 [acesso 2009 jan 9]; 13(2):73-80. Disponível em: <http://www.scielo.br>. doi: 10.1590/S1415-527 32000000200001.

27. Veiros MB. Análise das condições de trabalho do nutricionista na atuação como promotor de saúde em uma unidade de alimentação e nutrição: um estudo de caso [mestrado]. Florianópolis: Universidade Federal de Santa Catarina; 2002.

28. Instituto Brasileiro de Orientação Alimentar. Promoção do consumo de frutas, legumes e verduras: o programa "5 ao dia". 2005 [acesso 2009 mar 23]. Disponível em: <www.5aodia.com.br/upload/ cartilha1.pdf>.

29. Fortes RC. Obesidade na infância e na adolescência. Rev Nutr Brasil. 2005; 4(3):167-73.

30. Monteiro CA, Mondini L, Souza ALM, Popkin BM. Evolução da desnutrição infantil. In: Monteiro CA. Velhos e novos males da saúde no Brasil: a evolução do país e suas doenças. São Paulo: Hucitec; 2000.

31. Abrantes MM, Lamonier JA, Colosimo EA. Prevalência de sobrepeso e obesidade nas regiões Nordeste e Sudeste do Brasil. Rev Assoc Med Bras [Internet]. 2003 [acesso 2009 jan 9]; 49(2):162-6. Disponível em: <http://www.scielo.br>. doi: 10.15 90/S0104-42302003000200034.

Recebido em: 2/6/2009

Versão final reapresentada em: 22/2/2010 Aprovado em: 12/5/2010 
